\title{
Partial characterization and antioxidant and antiproliferative activities of the aqueous extracellular polysaccharides from the thermophilic microalgae Graesiella sp.
}

\author{
Lamia Trabelsi ${ }^{1} \mathbb{D}$, Olfa Chaieb ${ }^{1}$, Amira Mnari ${ }^{2}$, Salwa Abid-Essafi ${ }^{3}$ and Lotfi Aleya ${ }^{4^{*}}$
}

\begin{abstract}
Background: For thousands of years, Tunisian geothermal water has been used in bathing. Indeed, thermal baths "Hammam" were recommended in the treatment of different type of illnesses as, for instance, for relaxing joints and soothing. The ability of microalgae to sustain at the high temperature makes them potential producers of high value thermostable bio-products. This study aimed to explore the therapeutic potential of the aqueous extracellular polysaccharides (AEPS) of the Tunisian thermophilic microalgae Graesiella sp. and to evaluate its physico-chemical characteristics.
\end{abstract}

Methods: Different parameters were used to characterize the AEPS. The dry weight, volatile dry weight, elemental analysis, monosaccharide composition and IR-spectroscopy analysis. Carbohydrate, uronic acid, ester sulfate and protein concentrations were also determined using colorimetric assay. AEPS was analyzed for its antioxidant propriety by means of total antioxidant capacity, DPPH radicals scavenging assay, ferrous chelating ability and hydroxyl and superoxide radical scavenging activity. The antiproliferative activity of AEPS was evaluated for HepG2 and Caco-2 cells using the MTT assay.

Results: The Graesiella sp. AEPS is found to be a hetero-sulfated-anionic polysaccharides that contain carbohydrate (52\%), uronic acids (23\%), ester sulfate (11\%) and protein (12\%). The carbohydrate fraction was formed by eight neutral sugars glucose, galactose, mannose, fucose, rhamnose, xylose, arabinose and ribose. The FT-IR revealed the presence of carboxyl, hydroxyl, amine and sulfate groups. AEPS showed high activity as reducing agent, high ferrous chelating capacity and caused a significant decrease in a concentration-dependent manner of hydroxyl radical. A moderate DPPH scavenging activity and a poor superoxide radical scavenging ability were also observed. AEPS treatment (from 0.01 to $2.5 \mathrm{mg} / \mathrm{ml}$ ) caused also a clear decrease of cell viabilities in a dose-dependent manner. The $I_{50}$ values obtained in HepG2 and Caco-2 cells were $1.06 \mathrm{mg} / \mathrm{ml}$ and $0.3 \mathrm{mg} / \mathrm{ml}$ respectively.

Conclusions: This study evidenced that the Graesiella sp. AEPS exhibits antioxidant and antiproliferative activities. The biological activities of this extract depend on its fine structural features. Further work will identify and purify the active polysaccharides to enhance our understanding of their complete structure and relationships with its function.

Keywords: Tunisian hot spring, Microalgae, Graesiella sp., Sulfated exopolysaccharides, Biological activities

\footnotetext{
* Correspondence: lotfi.aleya@univ-fcomte.fr

${ }^{4}$ Université de Bourgogne Franche-Comté, Laboratoire de

Chrono-Environnement, UMR CNRS 6249, Besançon, France

Full list of author information is available at the end of the article
} 


\section{Background}

Microalgae are a novel source of sustainable natural products with various applications as pharmaceuticals $[1,2]$ nutraceuticals and food supplements [3]. Nowadays, a particular interest is conducted to isolate microalgae from extreme environments such as hot springs as a good source of natural products for diverse biotechnological demand [4-6]. Presently, interest is being remunerated to the isolation and identification of new microalgae strains from thermal springs. The target is the exceptional and the distinctive adaptation of these microorganisms under the influence of both heat and thermal stress. This extraordinary ability to harsh high temperature makes them prospective producers of high value thermostable bio-products and a valuable source for exploitation in new biotechnological progressions. The tolerance of thermophilic microorganisms to thermal environments is generally attributed to exopolysaccharides (EPS). EPS are defined as high molecular weight biopolymers that put together a substantial component of the extracellular polymers surrounding microbial cells membrane in the aquatic environment [6]. Exopolysaccharides in general, and sulphated exopolysaccharides in particular, are released by diverse species of microalgae (Chlorella stigmatophora, Chlorella sp., Tetraselmis sp., Cylindrotheca closterium...) and serve as antioxidant, anti-inflammatory, antiviral and as lubricating bone joints [7].

The Tunisian geothermal resources are characterized by their "Continental Intercalaire" origin, their sulfatechloride type and their hot water $\left(30-80{ }^{\circ} \mathrm{C}\right)$ [8]. For thousands of years, Tunisian geothermal water has been used for bathing. Indeed, thermal baths "Hammam" were recommended for the treatment of different type of illnesses as, for example, joint pain, soothing chest and back pain [9].

Therefore, as a part of our effort to further explore the therapeutic potential of the Tunisian hot spring water containing microalgae and the extracellular polysaccharides released by these microautotrophs, we felt it worthwhile to undertake a systematic study of the antioxidant and antiproliferative activity of the aqueous extracellular polysaccharides from the Tunisian thermophilic microalgae Graesiella sp and evaluate its physicochemical characteristics.

\section{Methods}

\section{Reagents}

Bovine serum albumin, monosaccharides (D-glucose, D-galactose, D-mannose, D-ribose, D-xylose, L-arabinose L-fucose, L-rhamnose), 1,1-diphenyl-2-picrylhydrazyl, Ascorbic acid, Earle's Minimum Essential Medium, Lglutamine, non-essential amino acids, penicillin, streptomycin, RPMI 1640 medium, HepG2 cells (Sigma
85011430) were from Sigma-Aldrich (France), foetal calf serum (Biosera, U.K.), TOP-Taq DNA polymerase (BIORON, Germany) Caco-2 cells were obtained from Dr. Jing Yu, Tufts School of Medicine (Medford, MA, USA). Other chemicals and solvents were of analytical grade.

\section{Microalgae and culture medium}

Samples were taken from 'Ain Echffa', a hot spring located in the N-E of Tunisia at water temperature of $60{ }^{\circ} \mathrm{C}$. Mats collected were treated by filtration, centrifugation and dilution techniques according to standard microbiological protocols [10]. The purified strain was grown in batch culture under sterile conditions in Bold's Basal Medium (BBM). The initial pH was adjusted to (6.8) according to Bischoff and Bold [11]. Cells were cultured in $20 \mathrm{~L}$ sterilized glass bottles sparkled with air. Cultures were maintained at $40{ }^{\circ} \mathrm{C}$, in light/dark cycles (16:8) with white fluorescent lamps providing $20 \mu \mathrm{mol}$ photons $\mathrm{m}^{-2} \mathrm{~s}^{-1}$.

\section{Strain identification}

Genomic DNA was extracted from the isolated strain using the hexadecyltrimethyl ammonium bromide (CATB) method described by Lefranc et al. [12].

The primers EukA (5'-AACCTGGTTGATCCTGCCAG T-3') and EukB (5'-TGATCCTTCTGCAGGTTCACCTAC-3') were used to amplify the $18 \mathrm{~S}$ rRNA gene. The PCR reaction was performed on a Thermocycler GeneAmp PCR System 9700 (Applied Bio systems) in a $50 \mu \mathrm{l}$ reaction mixture containing $0.2 \mathrm{mM}$ each $\mathrm{dNTP}, 0.2 \mu \mathrm{M}$ each primer, 50 ng DNA template, and 2.5 U TOP-Taq DNA polymerase with reaction buffer supplied by the manufacturer. The PCR program, was as follows: denaturation for $3 \mathrm{~min}$ at $94{ }^{\circ} \mathrm{C}$ and subjected to 30 cycles for $45 \mathrm{~s}$ at $94{ }^{\circ} \mathrm{C}, 1 \mathrm{~min}$ at $55^{\circ} \mathrm{C}$ and $2 \mathrm{~min}$ at $72{ }^{\circ} \mathrm{C}$, followed by a final elongation step for $10 \mathrm{~min}$ at $72{ }^{\circ} \mathrm{C}$. Reactions without template DNA were performed as negative controls. PCR products were purified and sequenced by society Biotools Tunisia. The primers used for sequencing were the same as those used for amplification. Target sequences were analyzed using BLAST online [13]. Multiple alignments were generated with the MUSCLE program and phylogenetic trees were constructed with MEGA program version 4 [14] on the basis of evolutionary distances that were calculated with a Neighbor-Joining method [15] with Maximum Composite Likelihood model. The bootstrap re-sampling analysis was performed for 1000 replicates to estimate degrees of confidence in tree topologies [16].

\section{EPS isolation and EPS aqueous extraction}

The EPS were purified, as described by Trabelsi et al. [17]. In brief, Grasiella culture, at the stationary phase, was being centrifuged $\left(4,000 \mathrm{rpm}, 10 \mathrm{~min}\right.$, at $\left.4{ }^{\circ} \mathrm{C}\right)$ to get culture filtrate containing both the released EPS and the 
culture medium. A tangential ultra-filtration cell (Millipore, Bedford. MA) and Millipore membranes (30 kDa pore size) have been used to concentrate EPS to remove low molecular weight compounds, EPS have been washed three times with deionized water. Finally, EPS was freezedried and lyophilized. The water-soluble EPS extract was prepared by mixing the lyophilized EPS with water during $30 \mathrm{~min}$ (ratio 40: $10 \mathrm{mg} / \mathrm{ml}$ ). The mixture was centrifuged (4000 rpm, $20 \mathrm{~min}, 4{ }^{\circ} \mathrm{C}$ ), the supernatant (which contains the EPS aqueous extract) was recovered and the residues were transferred back into extraction flask and mixed with distilled water. The procedure was repeated thrice. After the extraction, the aqueous extracellular polysaccharides (AEPS) was concentrated using a freeze dryer (Telstor Lyoalfa 6, Spain). The concentrated AEPS was weighed and new extract solutions were prepared for subsequent bioassays. The extract was preserved at $4{ }^{\circ} \mathrm{C}$. The extraction yield was determined as the percentage of extracted EPS to total EPS content [Extraction yield $(\%)=($ mass of extracted EPS/mass of total EPS) $\times 100]$.

\section{General analysis}

To characterize Graziella AEPS, various parameters have been identified. The dry weight (DW) and volatile dry weight (VDW) were evaluated by heating the EPS to 105 and to $550{ }^{\circ} \mathrm{C}$, respectively. The elemental analysis was carried using Flash Elemental Analyzer 1112 (ThermoQuest, Milan, Italy). Carbohydrate and uronic acid concentrations were estimated using the phenol/sulfuric acid assay [18] and carbazole assay [19] respectively. Ester sulfate was measured as described by Craigie et al. [20] with potassium sulfate as the standard. Protein concentration was determined the BCA method (bicinchoninic acid) according to the manufacturer's instructions (Sigma-Aldrich) with bovine serum albumin as the standard.

\section{Monosaccharide composition}

The AEPS sugar content was evaluated by methanolyse and silylation followed by gas chromatography according to Trabelsi et al. [21]. In brief, AEPS samples (1 mg) were methanolysed in $2 \mathrm{M}$ anhydride acid in methanol $\left(24 \mathrm{~h}, 80^{\circ} \mathrm{C}\right)$ for measurement of individual sugars with myoinositol as an internal standard. Samples were sylilated (in $1 \%$ trimethylchlorosilane in $\mathrm{N}$, O-bis (trimethylsilylfluoroacetamide) at $4{ }^{\circ} \mathrm{C}$ overnight) and analyzed by gas chromatography on capillary column DB 225 (J.W. Instruments) using nitrogen as the carrier gas and an air-hydrogen mixture as fuel.

\section{IR-spectroscopy analysis}

AEPS were vacuum dried and desiccated to FT-IR (Fourier-transform infrared) analysis. The FTIR spectra of AEPS were recorded using a golden-gate Diamond single reflectance system in FTS 7000 FT6IR spectrometer equipped with a DTGS detector (DIGILAB, MA, USA) and the spectra were scanned from 4000 to $800 \mathrm{~cm}^{-1}$.

\section{Antioxidant activity analysis \\ Total antioxidant capacity}

The tubes containing the AEPS and reagent solution (28 $\mathrm{mM}$ sodium phosphate, $4 \mathrm{mM}$ ammonium molybdate and $0.6 \mathrm{M}$ sulfuric acid) were incubated for $90 \mathrm{~min}$ at $95{ }^{\circ} \mathrm{C}$. After the mixture cooling (room temperature), the solution absorbance was measured at $695 \mathrm{~nm}$ against a blank. The antioxidant capacity was expressed as $\mathrm{mg}$ of ascorbic acid equivalent/g of sample.

\section{DPPH radicals scavenging assay}

The DPPH (1,1-dihpenyl-2-picrylhydrazyl) scavenging ability was investigated according to Shimada et al. [22]. Briefly, $1 \mathrm{ml}$ of sample solution at different concentrations $(0.01-2.0 \mathrm{mg} / \mathrm{ml})$ was added to $3 \mathrm{ml}$ of DPPH ethanol solution $(0.004 \%)$, and the absorbance was determined at $517 \mathrm{~nm}$ after $30 \mathrm{~min}$.

\section{Ferric chelating}

To evaluate the ferric chelating ability, we have used the method described by Telles et al. [23]. Briefly, the tubes that contained samples at different concentrations $(0.01-2.0 \mathrm{mg} / \mathrm{ml}), 0.2 \mathrm{ml}$ ferrozine $(5 \mathrm{mM})$ and $0.05 \mathrm{ml}$ $\mathrm{FeCl}_{2}(2 \mathrm{mM})$ were blended and incubated at room temperature for $10 \mathrm{~min}$. The sample absorbance was measured at $562 \mathrm{~nm}$.

\section{Hydroxyl radical scavenging activity assay}

Hydroxyl radicals scavenging ability was estimated according to Smirnoff and Cumbes [24]. In the test tubes, $0.5 \mathrm{ml}$ of sample solution at different concentrations $(0.01-2.0 \mathrm{mg} / \mathrm{ml})$ was added to the mixture of $0.3 \mathrm{ml}$ of orthophenanthroline $(5 \mathrm{mmol} / \mathrm{L}), 0.8 \mathrm{ml}$ of phosphate buffer $\mathrm{pH} 7.4(0.75 \mathrm{~mol} / \mathrm{L}), 0.3 \mathrm{ml}$ of $\mathrm{FeSO}_{4}(7.5 \mathrm{mmol} / \mathrm{L})$ and $0.2 \mathrm{ml}$ of $\mathrm{H}_{2} \mathrm{O}_{2}(1 \%)$. The reaction mixture was incubated for $60 \mathrm{~min}$ at $37{ }^{\circ} \mathrm{C}$ and the absorbance was measured at $532 \mathrm{~nm}$.

\section{Superoxide radical scavenging activity assay}

Superoxide radicals scavenging ability was assessed according to Marklund and Marklund [25]. Briefly, the mixture of $1 \mathrm{ml}$ of samples solution at different concentrations $(0.01-2.0 \mathrm{mg} / \mathrm{ml})$ and $3 \mathrm{ml}$ of Tris$\mathrm{HCl}$ buffer $\mathrm{pH} 8.2(0.05 \mathrm{~mol} / \mathrm{L})$ was incubated at $25^{\circ}$ $\mathrm{C}$ for $10 \mathrm{~min}$. At the same temperature $\left(25^{\circ} \mathrm{C}\right)$, $200 \mu \mathrm{l}$ of pyrogallol were added to the mixture, the reaction was proceed for $4 \mathrm{~min}$ and at the end $0.5 \mathrm{ml}$ of $\mathrm{HCl}$ was added. The absorbance was measured at $320 \mathrm{~nm}$ against the blank. 
The scavenging ability of DPPH, Hydroxyl and Superoxide radical scavenging activity assays and the ferrous ion chelating ability were calculated according to the following equation: scavenging ability/ chelating ability $(\%)=\left(1-\mathrm{A}_{\text {sample }} / \mathrm{A}_{\text {control }}\right) \times 100$. $\mathrm{A}_{\text {control: }}$ : Absorbance without the tested samples (control), $\mathrm{A}_{\text {sample }}$ : Absorbance in the presence of the tested samples.

Ascorbic acid was used as positive control in Total Antioxidant Capacity, DPPH radicals scavenging assay, Hydroxyl radical scavenging activity assay and Superoxide radical scavenging activity assay. EDTA was used as positive control in Ferric Chelating assay.

\section{Antiproliferative activity analysis}

The antiproliferative activity of AEPS was evaluated for HepG2 cells (human hepatocellular carcinoma) and Caco-2 cells (human colon cancer cell line) using the MTT assay [26]. HepG2 cells were cultivated in Dulbecco's modified Eagle's medium (DMEM) as monolayer cultures. Caco-2 cells were cultivated in DMEM medium with a high glucose concentration $(4.5 \mathrm{~g} / \mathrm{l})$. All media were complemented with foetal calf serum (10\%), l-glutamine (200 mM) (1\%), mixture penicillin $(100 \mathrm{IU} / \mathrm{ml})(1 \%)$ and streptomycin $(100 \mathrm{~g} / \mathrm{ml})$ and incubated in an atmosphere of $5 \%$ $\mathrm{CO}_{2}$ at $37{ }^{\circ} \mathrm{C}$. HepG2 and Caco-2 Cells were grown on 96-well culture plates (Polylabo, France) at $10^{5}$ cells/well and treated with rising concentrations of AEPS $(0-2.5 \mathrm{mg} / \mathrm{ml})$ for $72 \mathrm{~h}$ at $37{ }^{\circ} \mathrm{C}$. After the reaction time, the culture medium was substituted by $200 \mu \mathrm{l}$ medium containing $0.5 \mathrm{mg} / \mathrm{ml}$ MTT. The plates were again incubated $3 \mathrm{~h}$ at $37{ }^{\circ} \mathrm{C}$. The medium was then substituted with $200 \mu \mathrm{l}$ of $\mathrm{HCl}$ /isopropanol $(0.04 \mathrm{M})$ to solubilize the converted purple dye in culture plates. The absorbance was determined at $545 \mathrm{~nm}$ using a spectrophotometer microplate reader (Dynatech 4000). The cell viability was calculated according to the equation: [ $\left(\mathrm{A}_{545}\right.$ treated cells $/ \mathrm{A}_{545}$ control cells) $\times 100]$. $\mathrm{IC}_{50}$ values were defined as the concentration inducing $50 \%$ of cell mortality.

\section{Statistical analysis}

For every antioxidant and antiproliferative assay, three samples were tested. Results were shown as means \pm standard deviation (SD). Statistical differences between controls and treated groups for all expressions were determined by Student's t-test. Differences were considered significant at $p<0.05$.

\section{Results and discussion}

\section{Strain identification}

The 18S rDNA from the isolate was sequenced via the primer pair EukA and EukB (1677 bases pair). Phylogenetic analysis exposed that the isolated strain was closely related to the genus Graesiella and showed $99.8 \%$ similarity with two Graesiella species: Graesiella emersonii [27] synonym: Chlorella emersonii [28] and Graesiella vacuolata [27], synonym: Chlorella emersonii var.globosa [28]. It belongs to the Chlorophyceae class, and it is grouped within the Chlamydomonadales order.

\section{Extraction and compositional analysis}

In this study, we have chosen to work with aqueous extract even if its extraction yield doesn't exceed $55 \%$. This choice is essentially based on two major causes. The first is the relatively little information in the literature about the biological activities of the water soluble extracellular polysaccharides from microalgae. The second is to avoid the use of hazardous substances from chemicals with the aim to reduce the danger of chemical exposure to humans and the environment.

The freeze-dried aqueous extracellular polysaccharides (AEPS) is whitish and has a porous structure. The AEPS was investigated for its carbohydrate, protein, uronic acid and ester sulfate contents by colorimetric assay. For its carbon, hydrogen, nitrogen and sulphur content, elemental analysis was used. Results revealed that the VDW/DW ratio of the AEPS was $87 \%$ and that the AEPS was mostly constituted of an organic fraction. The molar ratio of hydrogen-carbon was lower than $2(1.7 \pm 0.2)$ which implies that AEPS is mainly composed of heteropolysaccharides. Results (Table 1) also showed that the AEPS was primarily composed of carbohydrate as indicated by phenol-sulfuric positive material, which reaches $52 \%$ of AEPS dry weight. The compositional analysis of the carbohydrate fraction shows that this component was formed by eight neutral sugars. These neutral sugars can be sorted as aldohexoses (glucose 12.1 \pm 3.1 , galactose $16.3 \pm 1.5$, mannose $11.5 \pm 4.2$ and fucose $32 \pm 6$ ), desoxyose (rhamnose $2.3 \pm 1.2$ ) and aldopentoses (xylose $10.3 \pm 2.6$, arabinose $12.5 \pm 4.6$ and ribose $2.7 \pm 0.6$ ) and the predominant sugar was fucose. The anionic nature of the AEPS was conferred by significant amounts of uronic acid. Uronic acid accounted for $23 \%$ of Graesiella AEPS dry weight. Another important anionic group in AEPS was ester sulfate. AEPS was highly sulfated $11 \%$ of dry weight. Protein was a secondary portion, although it represents only $12 \%$ of dry weight. Considering uronic acid and ester sulfate as components of the EPS polysaccharide portion, we can conclude that the Graesiella sp. AEPS is a heteroanionic-sulfated polysaccharides. Raposo et al. [7] demonstrated that among the extracellular polysaccharides focused on their review paper, only the extracellular polysaccharides of Gyrodinium impudicum is a homopolymer and that all the other extracellular polysaccharides from the other microalgae have been heteropolymers, mainly constituted of glucose, galactose, xylose and mannose. Other sugars such as fucose, frucose and rhamnose might 
Table 1 Chemical composition and monosaccharide composition of Graesiella sp. AEPS

\begin{tabular}{llllllllll}
\hline Protein & Ester sulfate & Uronic acid & \multicolumn{1}{l}{ Carbohydrate } & & & & \\
$12 \%$ & $11 \%$ & $24 \%$ & $53 \%$ & & & & & \\
& & $\%$ Monosaccharide composition & & & & \\
\hline & & Fuc & Gal & Ara & Glc & Man & Xyl & Rib & Rha \\
& & $32 \pm 6$ & $16.3 \pm 1.5$ & $12.5 \pm 4.6$ & $12.1 \pm 3.1$ & $11.5 \pm 4.2$ & $10.3 \pm 2.6$ & $2.7 \pm 0.06$ & $2.3 \pm 1.2$ \\
\hline
\end{tabular}

also be part of the EPS composition. The percentages of sulfate residues are different $(0-13.3 \% \mathrm{~W} / \mathrm{W})$ between the extracellular sulfated polysaccharides of the various strains of microalgae. The authors reported also a common property of all microalgae extracellular polysaccharides investigated, which is the anionic character of these polymers. This character is mainly due to the existence of ester sulfate and glucuronic acid groups. All these previous observations are in good accordance with our results.

\section{IR-spectroscopy analysis}

The IR spectrum (Fig. 1) of the aqueous extracellular polysaccharides, obtained from graesiella culture medium displayed a medium stretch of frequency range $3500-3300 \mathrm{~cm}^{-1}$ that corresponded to the stretching vibration of $-\mathrm{NH} 2$ group and $-\mathrm{OH}$ group. A weak aliphatic $\mathrm{CH} 2$ absorption band was also noticed at approximately $2910 \mathrm{~cm}^{-1}$ (asymmetric stretching). The medium bend of frequency range $1660-1570 \mathrm{~cm}^{-1}$ was attributed to $\mathrm{N}-\mathrm{H}$ stretching. The stretch monitored at 1410 resulted from the stretching vibration of $\mathrm{C}=\mathrm{O}$ (carboxylates function) and deformation vibration of $\mathrm{OH}$ (alcohols and phenols). The medium stretch of frequency range $1200-1100 \mathrm{~cm}^{-1}$ could be attributed to the stretch vibration of $\mathrm{C}-\mathrm{O}-\mathrm{C}, \mathrm{C}-\mathrm{O}$, corresponds to the presence of carbohydrates [29] and/or the presence of sulphate groups as $\mathrm{S}=\mathrm{O}$ and $\mathrm{C}-\mathrm{O}-\mathrm{S}$ [30].

\section{Antioxidant activity}

Substrates oxidation takes place across a chain reaction implicating three different stages: initiation, propagation and termination [31]. Thus, we tested various methods to evaluate AEPS effects on initiation (DPPH assay and Total Antioxidant Capacity: TAC), propagation (iron chelating) and termination (hydroxyl and superoxide radical scavenging activities) stages.

Results of the Total Antioxidant Capacity of the AEPS showed a TAC relative to $8.08 \mathrm{mg}$ AAE (Ascorbic Acid Equivalent)/g of sample. AEPS showed high activity as reducing agent. In fact, several authors [32, 33] considered that $9.2 \mathrm{mg} / \mathrm{g}$ of acid ascorbic equivalents a high antioxidant activity.

The AEPS antioxidant activity was also determined by DPPH assay. Results for the different concentrations of AEPS (Fig. 2) obviously showed that the AEPS displayed a moderate radical scavenging activity and that its scavenging ability was significantly lower to those of vitamin $C(p<0.05)$. The highest activity was reached using $2 \mathrm{mg} / \mathrm{ml}$ of AEPS, which attained only $43.2 \pm 1.4 \%$ of DPPH scavenging. DPPH assay is commonly used to determine the antioxidant of flavonoïd and phenolic compounds [34] rather than antioxidant activities of polysaccharide compounds, major component, in AEPS of Graesiella sp. In another study, the aqueous extract of Chlorella vulgaris extracellular polysaccharides showed an activity of about $109.02 \pm 8.25 \%$ of radical scavenging in DPPH assay [35]. With regard to our data, there is a dissimilarity in results. This difference is essentially assigned to the biochemical composition of the aqueous extract for each extracellular polysaccharide. Indeed, the EPS aqueous extract of Chlorella vulgaris was rich in phenolic compounds whereas the EPS aqueous extract of Graesiella sp. was rich in sulfated polysaccharides.

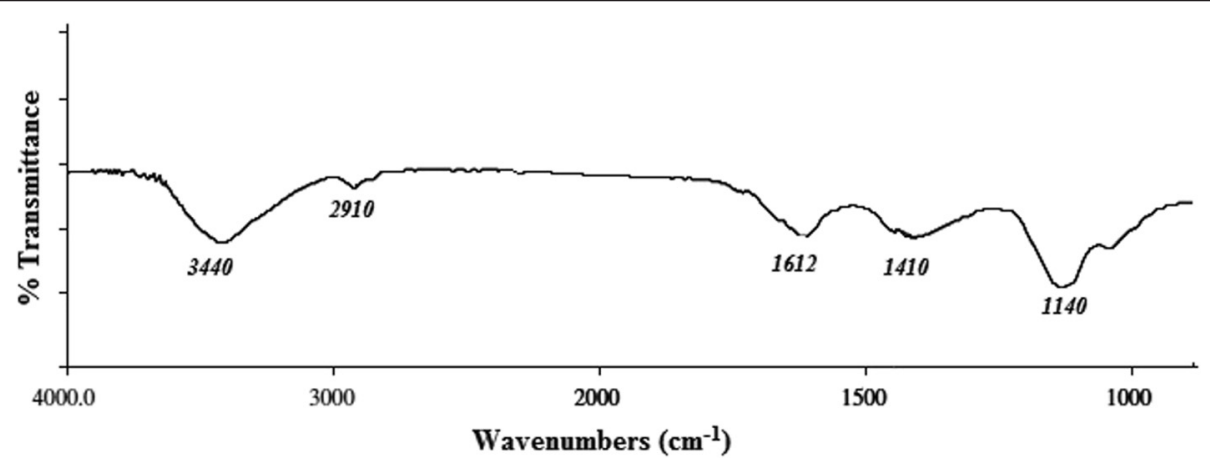

Fig. 1 Infrared spetrum of Graesiella sp. AEPS 


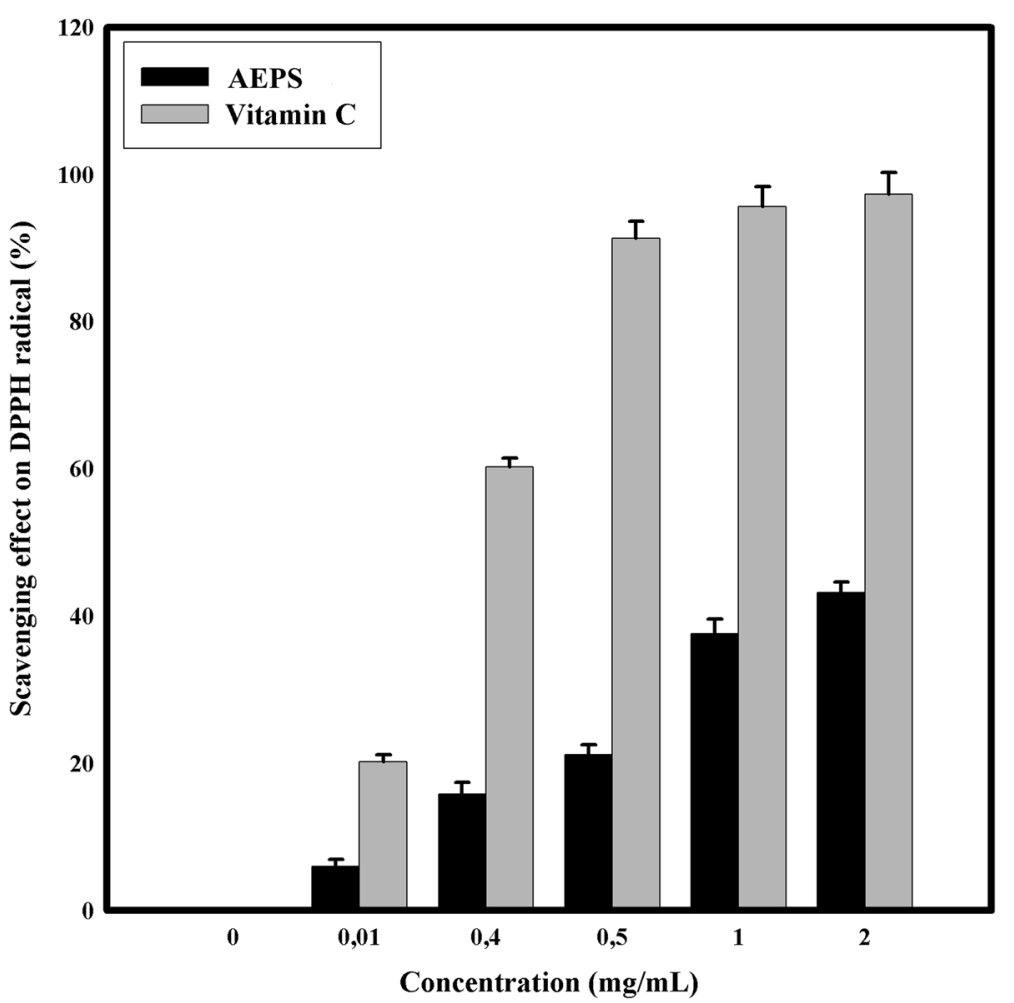

Fig. 2 DPPH radical scavenging activity of AEPS at different concentrations. Values are means \pm SD $(n=3)$

The results of the AEPS chelating effect are depicted in Fig. 3. The AEPS from Graesiella sp. presented a high ferrous chelating capacity with an $\mathrm{IC}_{50}=0.33 \mathrm{mg} / \mathrm{ml}$, and it was apparent that this capacity was dosedependent. When compared to EDTA (used at the same EPS concentrations), the AEPS showed the highest values of chelating ability. In fact, the maximum chelating capacity was $98.2 \pm 3 \%$ and it was reached using $2 \mathrm{mg} / \mathrm{ml}$ of AEPS. At the concentrations 0.5 and $1 \mathrm{mg} / \mathrm{ml}$, the iron chelating activity of the AEPS was respectively 1.24 and 1.18 times higher than EDTA activity $(p<0.05)$, under the same experimental conditions. The chelating ability of compound is described by Melo-Silveira et al. [31] as: "the formation of bonds between two or more binding sites within the same molecule and a single central atom". This specificity was mostly observed in organic substances like polysaccharides, which have the ability to bind to metal atoms from chelate [36]. This, lead us inevitably to predict that the high percentage of polysaccharides in the AEPS allows the high ability in iron chelating. The ferrous ions are generally considered as the most powerful prooxidants for food systems [37]. The high chelating ability of the AEPS showed that the latter might be formulated into food.

One of the most reactive oxygen species in the body is the hydroxyl radical. It severely damages proximate bio- molecules (DNA, protein) resulting into mutagenesis, carcinogenesis and cytotoxicity [38]. Then, removing hydroxyl radical from living organisms protects them from different illness and diseases. Figure 4 showed the hydroxyl radical scavenging ability of the AEPS. AEPS exhibited a significant decrease in a concentrationdependent manner of hydroxyl radical. The maximal inhibition value was $65.2 \% \pm 4.7$ at $2 \mathrm{mg} / \mathrm{ml}$ and the $\mathrm{IC}_{50}$ value was $0.87 \mathrm{mg} / \mathrm{ml}$. Indeed, the AEPS can be considered as a potent quenchers of $\mathrm{OH}$ radical when compared to the ascorbic acid $\left(\mathrm{IC}_{50}=1.1 \mathrm{mg} / \mathrm{ml}\right)$. Our previous result is in concordance with an earlier published paper [39]. Moreover, it leads us to propose that the hydroxyl radical scavenging capacity of Graesiella sp. AEPS could help human body to prevent oxidative damage.

In the current study and as shown in Fig. 5. the Graesiella sp. AEPS was poor effective superoxide radical scavengers compared to vitamin $C(p<0.05)$. Several works $[40,41]$ have demonstrated that the superoxide radical scavenging ability is dependent on sulfate content. In fact, the highly sulfated polysaccharides were more effective than the less sulfated polysaccharides. The sulfate content on the AEPS found herein is $11 \%$ of dry weight. However, the maximal inhibition value was $15.2 \% \pm 2.4$ at $2 \mathrm{mg} / \mathrm{ml}$. Costa et al. [42] suggested that 


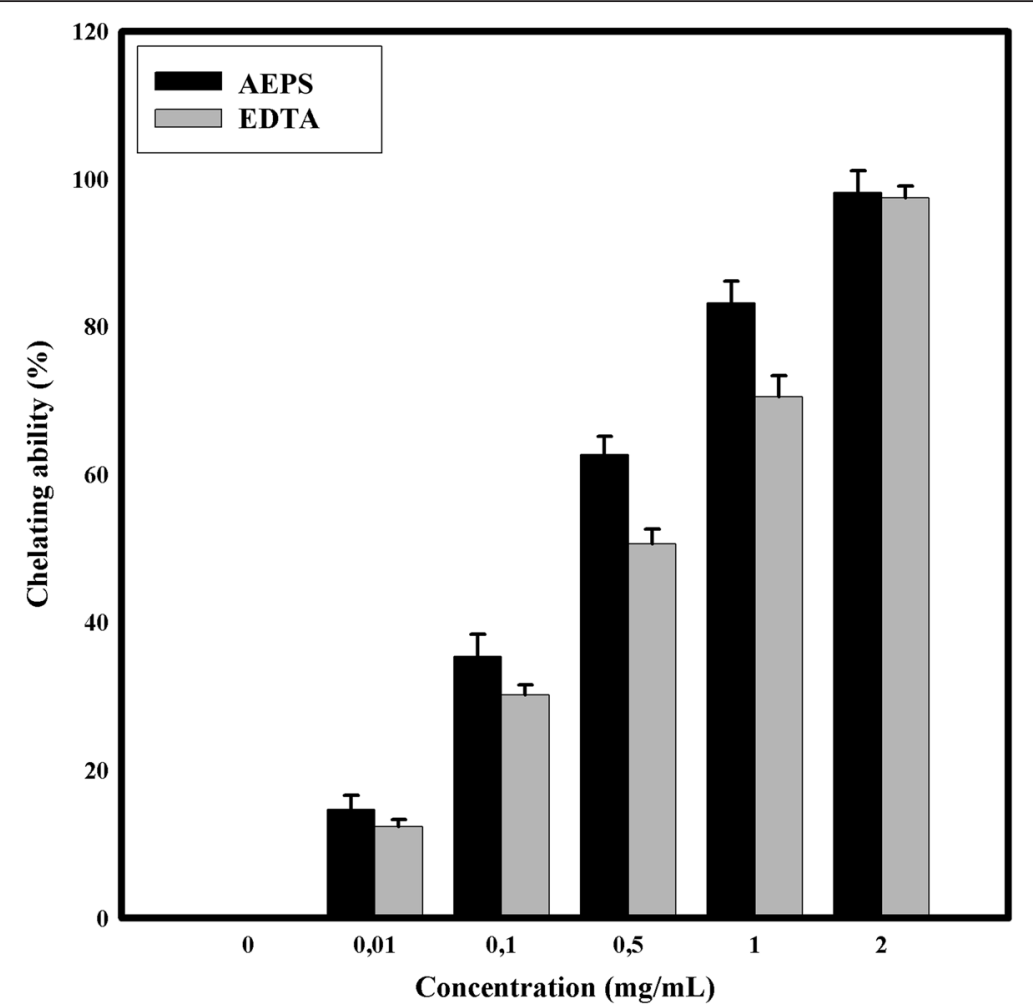

Fig. 3 Chelating ability of AEPS at different concentrations. Values are means \pm SD $(n=3)$

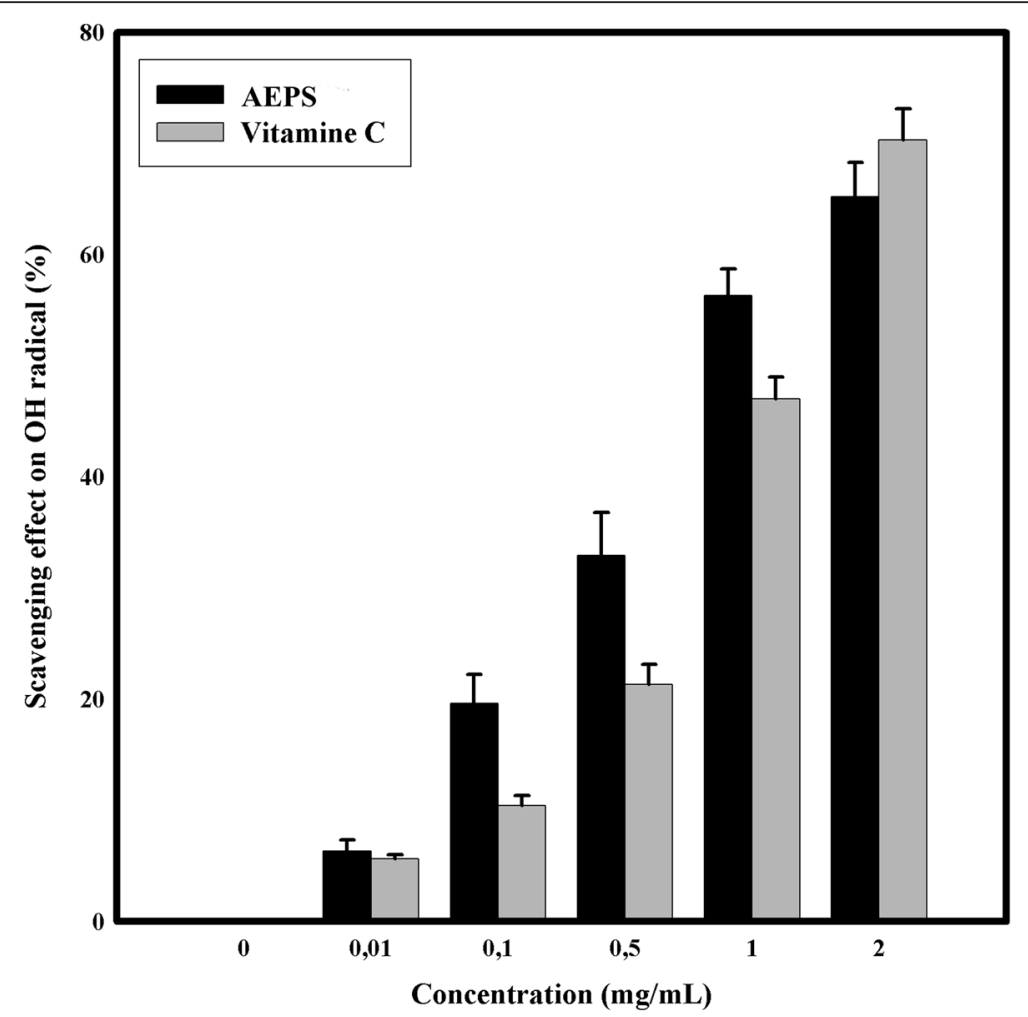

Fig. 4 Hydroxyl radical scavenging activity of AEPS at different concentrations. Values are means \pm SD $(n=3)$ 


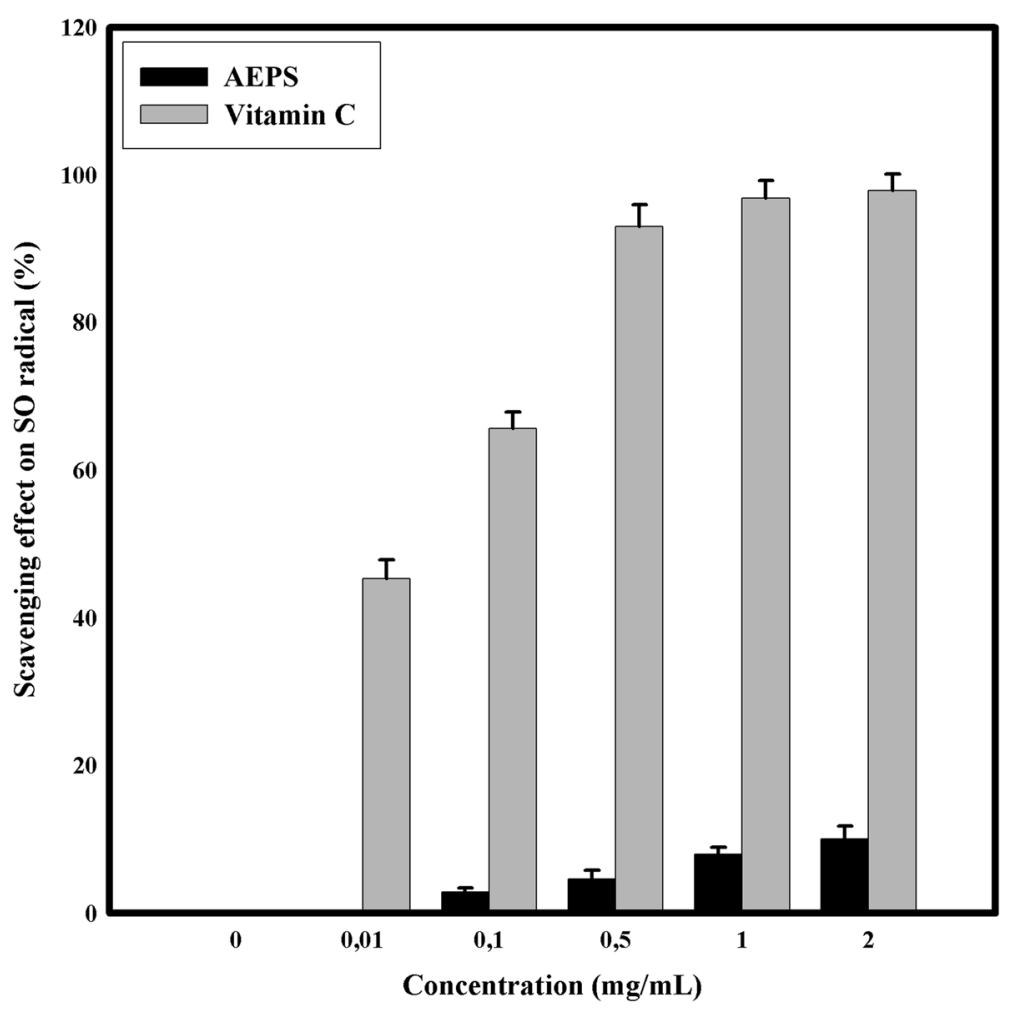

Fig. 5 Superoxide scavenging activity of AEPS at different concentrations. Values are means \pm SD $(n=3)$

the superoxide anion scavenging ability was more dependent on spatial patterns of the sulfated group than to the sulfate content.

As far as we know, there is relatively modest information about spatial patterns of sulfate group water soluble antioxidants from microalgae extracellular polysaccharides $[35,40,43,44]$ along with their mechanisms at the molecular level. Tannin-Spitz et al. [43] demonstrated that the antioxidant activity of the extracellular polysaccharides from Porphyridium was correlated positively with sulfate content, and pointed out the glycoprotein potentials to contribute to the antioxidant activity. However, Hajimahmoodi et al. [35] showed that the antioxidant activity of the water soluble extracellular polysaccharides correlated with phenolic content. Molecular weight was also an influential factor on the antioxidant activity. Sun et al. [44] demonstrated that the low-molecular-weight fragment of the extracellular polysaccharides from Porphyridium cruentum after degradation had stronger antioxidant activity than the other fragments.

\section{Antiproliferative activity}

Additionally to their antioxidant activity, extracellular sulfated polysaccharides are also known by other pharmacological properties like the antiproliferative activity [7].
Thus, to estimate the antiproliferative propriety of AEPS, the latter was essayed against two human cancer cell lines: Caco-2 and HepG2 cells.

Figure 6 indicates that AEPS treatment (from 0.01 to $2.5 \mathrm{mg} / \mathrm{ml}$ ) caused a clear decrease of HepG2 and Caco-2 cells viabilities in a dose-dependent manner. AEPS showed $\mathrm{IC}_{50}=0.3 \mathrm{mg} / \mathrm{mL}$ with $91 \%$ inhibition of cell growth at $2.5 \mathrm{mg} / \mathrm{ml}$ for Caco-2 cell line. For HepG2 cells, the $\mathrm{IC}_{50}$ value obtained was $1.06 \mathrm{mg} / \mathrm{ml}$ and $2.5 \mathrm{mg} / \mathrm{ml}$ AEPS caused $70.4 \%$ of inhibition cell growth. Moreover, we can observe that there was a considerable difference in the sensitivity of the two cell lines (HepG2 and Caco-2) to AEPS. In fact, Caco2 cells were more sensitive than HepG2 cells at the same concentration and under the same experimental conditions. In another study, Gardeva et al. [45] reported that water soluble extracellular sulfated polysaccharides from the microalgae Porphyridium cruentum exhibited strong anti-tumor activity against Graffi myeloide tumors in hamsters. They also found that this activity was dose-dependent, inferring that the antitumor activity could be related to the immunostimulating properties of sulfated polysaccharides. Moreover, Geresh et al. [46] found that the "oversulfated" (having sulfate contents exceeding $20 \%$ ) extracellular polysaccharides from Porphyridium sp. inhibited neoplastic mammalian 


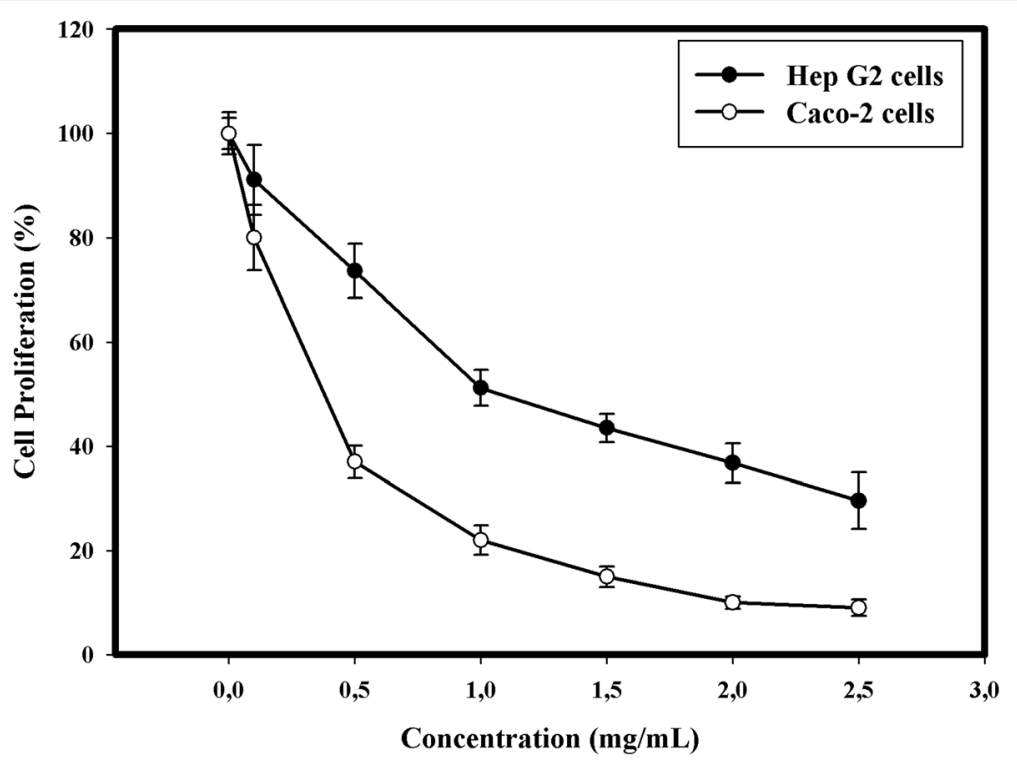

Fig. 6 Percentage inhibition of HepG2 and Caco-2 cells proliferation by the AEPS at different concentrations. Values are means \pm SD $(n=3)$

cell growth. To our knowledge, there is little information concerning cancer preventive and anticarcinogenic properties of extracellular sulfated polysaccharides from marine microalgae. Meanwhile, certain studies have proven that sulfated polysaccharide exhibit in vitro and in vivo anti-tumor activity, but their precise action mechanisms are not yet totally understood [47].

\section{Conclusion}

This work has gathered experimental evidence that the aqueous extracellular polysaccharides from the Tunisian thermophilic microalgae Graesiella sp. is a hetero-anionic-sulfated polysaccharide, and it displays potential pharmacological activities. In fact, the Graesiella sp. AEPS showed in vitro high values in total antioxidant capacity, iron chelating ability and hydroxyl radicals scavenging activity. These high antioxidant proprieties were probably due to the high amount of polysaccharides, ester sulfate and uronic acid compounds in the aqueous extract. Additionally, AEPS showed antiproliferative activity against two cancer cell lines (Caco-2 and HepG2), and its possible mechanism of action may be related to the sulfate groups. However, these findings warrant extensive studies on chemical structure and physicochemical characteristics including the rheological properties and molecular weight, as these parameters appear to be relevant to their function and behavior. The study will be helpful to understand this important fraction of extracellular polysaccharides and further studies are underway in our laboratory.

\section{Abbreviations}

$A A E$, ascorbic acid equivalent; AEPS, aqueous extracellular polysaccharides; BBM, bold's basal bedium; BCA, bicinchoninic acid; BLAST, basic local alignment search tool; CATB, hexadecyltrimethyl ammonium bromide; DMEM, Dulbecco's modified Eagle's medium; DNA, deoxyribonucleic acid; DPPH, 1,1-dihpenyl-2-picrylhydrazyl; DW, dry weight; EDTA, ethylenediamine-tetra-acetic acid; EPS, extracellular polysaccharides; FT-IR, Fouriertransform infrared; $I C_{50}$, 50-percent inhibition concentration; MEGA, molecular evolutionary genetics analysis; $\mathrm{PCR}$, polymerase chain reaction; SD, standard deviation; TAC, total antioxidant capacity; VDW, volatile dry weight; \%WN, weight per weight percent

\section{Acknowledgements}

This work was supported by the Tunisian contract program of the IRESA (Institution de la Recherche et de l'Enseignement Supérieur Agricole), National Institute of Marine Sciences and Technology, Laboratory of Marine Biodiversity and Biotechnology.

\section{Funding}

The authors declare that they have received no funding for the research reported.

\section{Availability of data and materials}

The datasets supporting the conclusions of this article are included within the article.

\section{Authors' contributions}

L. Trabelsi studied the concept, designed the experiments and wrote the manuscript. L. Trabelsi, O. Chaieb, A. Mnari, and S. Abid-Essafi carried out the experiments and analyzed the data. Lotfi Aleya supervised the study and participated in the manuscript preparation. All authors read and approved the final manuscript.

\section{Competing interests}

The authors declare that they have no competing interests that might have influenced the performance of the work described in this manuscript.

Consent for publication

Not applicable.

Ethics approval and consent to participate Not applicable. 


\section{Author details}

'Laboratory of Marine Biodiversity and Biotechnology, National Institute of Marine Sciences and Technology, BP 59, 5000 Monastir, Tunisia.

${ }^{2}$ Biochemistry Laboratory, Research Laboratory in "Nutrition- Functional Food \& Vascular Health" Faculty of Medicine of Monastir, 5019 Monastir, Tunisia. ${ }^{3}$ Laboratory of Research on Biologically Compatible Compounds, Faculty of Dentisty, 5019 Monastir, Tunisia. ${ }^{4}$ Université de Bourgogne Franche-Comté, Laboratoire de Chrono-Environnement, UMR CNRS 6249, Besançon, France.

\section{Received: 18 December 2015 Accepted: 7 July 2016}

\section{Published online: 12 July 2016}

\section{References}

1. Abdel-Daim MM, Abuzead SM, Halawa SM. Protective role of Spirulina platensis against acute deltamethrin-induced toxicity in rats. PLoS One. 2013;8:e72991

2. Abdel-Daim MM, Farouk SM, Madkour FF, Azab SS. Anti-inflammatory and immunomodulatory effects of Spirulina platensis in comparison to Dunaliella salina in acetic acid-induced rat experimental colitis. Immunopharmacol Immunotoxicol. 2015;37:126-39.

3. Koller M, Muhr A, Braunegg G. Microalgae as versatile cellular factories for valued products. Algal Res. 2014;6:52-63.

4. Mutanda T, Ramesh D, Karthikeyan S, Kumari S, Anandraj A, Bux F. Bioprospecting for hyper-lipid producing microalgal strains for sustainable biofuel production. Bioresource Technol. 2011;102:57-70.

5. Seckbach J. Algae and cyanobacteria in extreme environments. 1st ed. Netherlands: Springer; 2007.

6. Poli A, Anzelmo G, Nicolaus B. Bacterial exopolysaccharides from extreme marine habitats: production, characterization and biological activities. Mar Drugs. 2010;8:1779-802.

7. Raposo MFDJ, De Morais RMSC, Bernardo de Morais AMM. Bioactivity and applications of sulphated polysaccharides from marine microalgae. Mar Drugs. 2013;11:233-52

8. Agoun A. Exploitation of the continental intercalaire aquifer at the Kebili geothermal field. Tunisia: Geothermal Training Programme; 2000. p. 28

9. Jackson R. Waters and spas in the classical world. Med Hist. 1990;10:1-13.

10. Guillard R. Purification methods for microalgae. 1st ed. San Diego: Elsevier science; 2005.

11. Bischoff HW, Bold HC. Phycological studies IV. In some soil algae from enchanted rock and related algal species. Austin, Tex: University of Texas Publication; 1963. p 1-95.

12. Lefranc $M$, Clément $O$, Kaas Q, Duprat E, Chastellan P, Coelho I, et al. IMGT-Choreography for immunogenetics and immunoinformatics. ISB. 2005;5:45-60

13. Altschul SF, Madden TL, Schäffer AA, Zhang J, Zhang Z, Miller W, Lipman DJ. Gapped BLAST and PSI-BLAST: a new generation of protein database search programs. Nucleic Acids Res. 1997;25:3389-402.

14. Tamura K, Dudley J, Nei M, Kumar S. MEGA4: Molecular Evolutionary Genetics Analysis (MEGA) Software Version 4.0. Mol Biol Evol. 2007;24:1596-9.

15. Saitou N, Nei M. The neighbor-joining method: a new method for reconstructing phylogenetic trees. Mol Biol Evol. 1987;4:406-25.

16. Felsenstein J. Confidence limits on phylogenies: an approach using the bootstrap. Evolution. 1985;39:783-91.

17. Trabelsi L, Ben Ouada H, Bacha H, Ghoul M. Combined effect of temperature and light intensity on growth and extracellular polymeric substance production by the cyanobacterium Arthrospira platensis. J Appl Phycol. 2009;21:405-12.

18. Dubois M, Gilles K, Hamilton JK, Rebers PA, Smith F. Colorimetric method for determination of sugars and related substances. Anal Chem. 1956;28:350-6.

19. Bitter T, Muir H. A modified uronic acid carbazole reaction. Anal Biochem. 1962:4:330-4

20. Craigie JS, Wen ZCP, Van der Meer J. Interspecific and nutritionallyDetermination Variations in the Composition of Agars from Gracilaria spp. Bot Mar. 1984;27:55-61

21. Trabelsi L, M'sakni NH, Ben Ouada H, Bacha H, Roudesli S. Partial characterization of extracellular polysaccharides from the cyanobacterium Arthrospira platensis. Biotechnol Bioprocess Eng. 2009;14:27-31.

22. Shimada K, Fujikawa K, Yahara K, Nakamura T. Antioxidative properties of xanthan on the autoxidation of soybean oil in cyclodextrin emulsion. J Agr Food Chem. 1992;40:945-8.
23. Telles CBS, Sabry DA, Almeida-Lima J, Costa MSSP, Melo-Silveira RF, Trindade $E S$, et al. Sulfation of the extracellular polysaccharide produced by the edible mushroom Pleurotus sajor-caju alters its antioxidant, anticoagulant and antiproliferative properties in vitro. Carbohyd Polym. 2011;85:514-21.

24. Smirnoff N, Cumbes QJ. Hydroxyl radical scavenging activity of compatible solutes. Phytochemistry. 1989;28:1057-60.

25. Marklund S, Marklund G. Involvement of the superoxide anion radical in the autoxidation of pyrogallol and a convenient assay for superoxide dismutase Eur J Biochem. 1974:47:469-74.

26. Mosmann T. Rapid colorimetric assay for cellular growth and survival: application to proliferation and cytotoxicity assays. J Immunol Methods. 1983;65:55-63.

27. Nozaki H, Katagiri M, Nakagawa M, Aizawa K, Watanabe M. Taxonomic re-examination of two strains labeled "chlorella" in the microbial culture collection at the national institute for environmental studies (NIES-collection). Microbial Culture Collections. 1995;11:11-8.

28. Shihira I, Krauss RW. Chlorella. Physiology and taxonomy of forty-one isolates. 1965. p. 1-97.

29. Parikh A, Madamwar D. Partial characterization of extracellular polysaccharides from cyanobacteria. Bioresource Technol. 2006;97:1822-7.

30. Stuart BH. Infrared spectroscopy: fundamentals and applications. USA: Wiley; 2004.

31. Melo-Silveira RF, Fidelis GP, Viana RLS, Soeiro VC, Silva RA, Machado D, et al. Antioxidant and antiproliferative activities of methanolic extract from a neglected agricultural product: corn cobs. Molecules. 2014;19:5360-78.

32. Kumar KS, Ganesan K, Rao PVS. Antioxidant potential of solvent extracts of Kappaphycus alvarezii (Doty) An edible seaweed. Food Chem. 2008;107:289-95.

33. Athukorala $Y$, Kim K-N, Jeon Y-J. Antiproliferative and antioxidant properties of an enzymatic hydrolysate from brown alga, Ecklonia cava. Food Chem Toxicol. 2006:44:1065-74.

34. Lucas-Abellán C, Mercader-Ros MT, Zafrilla MP, Gabaldón JA, Núñez-Delicado E. Comparative study of different methods to measure antioxidant activity of resveratrol in the presence of cyclodextrins. Food Chem Toxicol. 2011;49:1255-60.

35. Hajimahmoodi M, Faramarzi M, Mohammadi N, Soltani N, Oveisi M, Nafissi-Varcheh N. Evaluation of antioxidant properties and total phenolic contents of some strains of microalgae. J Appl Phycol. 2010;22:43-50.

36. Kim S-G, Ahn H-R, Lee K-H. Pervaporation characteristics of polyelectrolyte complex gel membranes based on two anionic polysaccharides having a chelating structure. Curr Appl Phys. 2009;9:42-6.

37. Wang $P$, Jiang $X$, Jiang $Y$, Hu X, Mou H, Li M, Guan $H$. In vitro antioxidative activities of three marine oligosacharides. Nat Prod Res. 2007;21:646-54.

38. Gülçin I, Elmastaş M, Aboul-Enein HY. Determination of antioxidant and radical scavenging activity of Basil (Ocimum basilicum L. Family Lamiaceae) assayed by different methodologies. Phytother Res. 2007;21:354-61.

39. Chen B, You W, Huang J, Yu Y, Chen W. Isolation and antioxidant property of the extracellular polysaccharide from Rhodella reticulata. World J Microb Biot. 2010;26:833-40

40. Qi H, Zhang Q, Zhao T, Chen R, Zhang H, Niu X, Li Z. Antioxidant activity of different sulfate content derivatives of polysaccharide extracted from Ulva pertusa (Chlorophyta) in vitro. Int J Biol Macromol. 2005;37:195-9.

41. Xing R, Liu S, Yu H, Guo Z, Li Z, Li P. Preparation of high-molecular weight and high-sulfate content chitosans and their potential antioxidant activity in vitro. Carbohyd Polym. 2005;61:148-54.

42. Costa LS, Fidelis GP, Cordeiro SL, Oliveira RM, Sabry DA, Câmara RBG, Rocha HAO. Biological activities of sulfated polysaccharides from tropical seaweeds. Biomed Pharmacother. 2010;64:21-8.

43. Tannin-Spitz T, Bergman M, Grossman S, Arad S. Antioxidant activity of the polysaccharide of the red microalga Porphyridium sp. J Appl Phycol. 2005;17:215-22.

44. Sun L, Wang C, Shi Q, Ma C. Preparation of different molecular weight polysaccharides from Porphyridium cruentum and their antioxidant activities. Int J Biol Macromol. 2009;45:42-7.

45. Gardeva E, Toshkova R, Minkova K, Gigova L. Cancer protective action of polysaccharide, derived from Red microalga Porphyridium Cruentum a biological background. Biotechnol Biotec Eq. 2009;23:783-7.

46. Geresh S, Mamontov A, Weinstein J. Sulfation of extracellular polysaccharides of red microalgae: preparation, characterization and properties. J Biochem Bioph Meth. 2002;50:179-87.

47. Wijesekara I, Pangestuti R, Kim S-K. Biological activities and potential health benefits of sulfated polysaccharides derived from marine algae. Carbohyd Polym. 2011;84:14-21. 